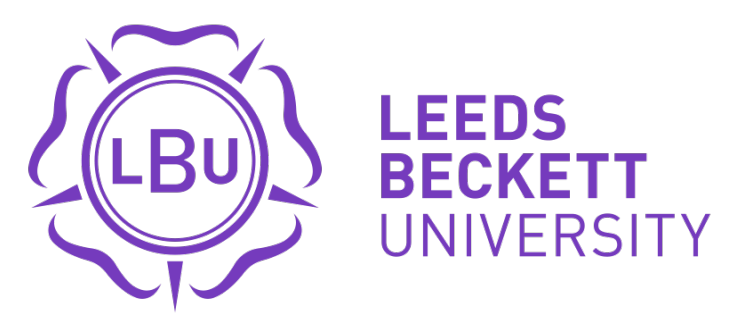

Citation:

Dohme, L and Boocock, E and Abraham, A and Piggott, D and Lara-Bercial, S (2015) International Sport Coaching Journal Digest. International Sport Coaching Journal / ISCJ, 2 (1). pp. 87-92. ISSN 2328-918X DOI: https://doi.org/10.1123/iscj.2014-0150

Link to Leeds Beckett Repository record:

https://eprints.leedsbeckett.ac.uk/id/eprint/3034/

Document Version:

Article (Accepted Version)

The aim of the Leeds Beckett Repository is to provide open access to our research, as required by funder policies and permitted by publishers and copyright law.

The Leeds Beckett repository holds a wide range of publications, each of which has been checked for copyright and the relevant embargo period has been applied by the Research Services team.

We operate on a standard take-down policy. If you are the author or publisher of an output and you would like it removed from the repository, please contact us and we will investigate on a case-by-case basis.

Each thesis in the repository has been cleared where necessary by the author for third party copyright. If you would like a thesis to be removed from the repository or believe there is an issue with copyright, please contact us on openaccess@leedsbeckett.ac.uk and we will investigate on a case-by-case basis. 


\section{INTERNATIONAL SPORT COACHING JOURNAL DIGEST VOLUME 2, ISSUE \#1}

Compiled by Lea Dohme, Emma Boocock, Andrew Abraham, Dave Piggott and Sergio LaraBercial from the Sport Coaching and Physical Education Research Centre at Leeds Beckett University, UK

Digest contains a listing of pertinent, recent coaching and coach education articles and updates from other sources.

\section{Instructional Strategies to Promote Incremental Beliefs in Youth Sport}

Vella, S.A., Cliff, D.P., Okely, A.D., Weintraub, D.L., \& Robinson, T.N. (2014). Quest, 66(4), 357-370.

This review addressed the application of implicit beliefs to the youth sport context. It proposed a theoretically derived, evidence-based, and conceptually related set of instructional strategies said to facilitate the promotion of incremental beliefs of athletic ability within youth sport contexts. Six specific instructional strategies were suggested for implementation by coaches, parents and other support staff: focusing on effort and persistence, facilitating challenges, promoting the value of failure, defining success as effort, the promotion of learning, and providing high expectations. These instructional strategies can be used to facilitate positive motivational, behavioural, and affective outcomes for young athletes.

\section{Psychological Resilience in Sport: A Review of the Literature and Implications for Research and Practice}

Galli, N. \& Gonzalez, S.P. (2014). International Journal of Sport and Exercise Psychology, 1, 115.

This review offers views on the current state of resilience research in sport, and offers suggestions for future research and sport interventions. Even though the focus of the article lies upon analysing the strengths and weaknesses of resilience in sport research, the authors do offer suggestions on how to enhance resilience in athletes based upon examples from resiliencebuilding programmes in other settings such as the military and education. It is suggested that interventions to enhance athlete resilience should be aimed at fostering protective factors and developing competencies, such as optimism, problem-solving skills, self-regulation skills, positive views of oneself and achievement goals in socially supportive environments. After the development of these factors, coaches and practitioners can then stimulate adversity for athletes in a caring and safe environment and work with them to develop and practice adaptive responses. 


\section{Adolescent Performers' Perspectives on Mental Toughness and its Development: The Utility of the Bioecological Model}

Mahoney, J. W., Gucciardi, D. F., Mallett, C. J., \& Ntoumanis, N. (2014). The Sport

Psychologist, 28, 233-244.

This qualitative research study was conducted to investigate adolescents' perspectives on mental toughness and its development across different performance contexts (i.e., sport, academia, \& music). In addition, the authors investigated if the identified perspectives align with Bronfenbrenner's (2001) bioecological model. Mental toughness was conceptualized by nine personal characteristics (i.e., persistence, drive, high self-expectations, support seeking, forethought, social intelligence, heightened awareness, self-belief, \& optimistic thinking) of which three had not been previously reported in mental toughness research with adult athletes. Additionally, mental toughness was found to be predicated on significant others, supportive social processes, critical incidents, and curiosity, and resonated with the properties of the bioecological model.

\section{Preparing Athletes and Teams for the Olympic Games: Experiences and Lessons Learned from the World's Best Sport Psychologists}

Arnold, R., \& Sarkar, M. (2014). International Journal of Sport and Exercise Psychology, 1, 117.

This panel-type article offers lessons and advice for the next generation of aspiring practitioners who are aiming to prepare athletes and teams for the Olympic Games. Fifteen renowned world class sport psychology practitioners were interviewed and 28 main themes and 5 categories that offer valuable advice to neophyte practitioners were identified. It was suggested that these tips can heighten aspiring practitioners' awareness of stressors athletes might encounter prior to, during, and after the Olympic Games. The importance of practitioners closely working together with athletes and their coaches is outlined.

\section{Enhancing the Provision of Coach Education: The Recommendations of UK Coaching Practitioners}

Nelson, L., Cushion, C. \& Potrac, P. (2013). Physical Education and Sport Pedagogy, 18(2), 204-218.

Coach Education, and the impact of it, has become somewhat of a 'hot topic' over the past two decades. Although coach education has been identified as a key vehicle for raising standards of coaching practice, it has been argued that the 'top-down' approach to the design and delivery of the courses is limiting the impact on learning and development. As a means to overcome the limited empirical data on the provision of coach education these authors conducted 16 in-depth semi-structured interviews and 74 open ended questionnaires to elicit their recommendations for 
future coach education environments. Their findings show that the coaches valued 1) relevant and usable course content delivered through pedagogical approaches that actively engage them in the learning process, 2) a range of learning resources and mentoring opportunities, and 3) economical influences, such as cost and facility, to be taken into consideration.

\section{Coach Learning and Coach Education: Portuguese Expert Coaches' Perspective} Mesquita, I., Ribeiro, J., Santos, S. \& Morgan, K. (2014).The Sport Psychologist, 28, 124-136.

Within this article the authors interview 6 Portuguese expert coaches to articulate their perceptions on the current situation of coach education in Portugal. The findings showed that the coaches externalised a constructivist learning conception advocating the importance of practical experience alongside the taught programme as an essential mechanism in promoting sustainable, long-term coach development program. More importantly the recommendations are not only for Portuguese coach education programs but a generic reflection on coach education in general.

\section{Coaches' Learning and Education: A Case Study of Cultures in Conflict}

Stodter, A., \& Cushion, C. (2014). Sports Coaching Review, 3(1), 63-79.

The longitudinal nature of this study aimed to explore the different learning cultures coaches experience, and how the dynamics of the cultures impact on a coaches' learning and knowledge. The multi method approach, tracking two coaches throughout their journey in the 'Youth Coaching Programme', provides a clear representation of 'what works' in coach education, compared to previous research within this area. Results showed there were clear discrepancies between the philosophies of the course and the coaches' cultures, highlighting the need for synergy between the two learning environments. The coaches showed minimal changes in their behaviour over the two years, as they relied heavily on their existing biographies to filter the information they were receiving to 'fit' their practice context.

\section{The Illusion of Competency versus the Desirability of Expertise: Seeking a Common Standard for Support Professions in Sport}

Collins, D., Burke, V. Martindale, A. \& Cruickshank, A. (2014). Sports Medicine.

http://link.springer.com/article/10.1007/s40279-014-0251-1

This paper challenges the Competency Based approach to defining professional practice and aligned development programmes and their assessment. The competency based approach is defined as one which focuses on behavioural outcomes. The alternative view on expertise identifies a need to view practice as a professional judgement and decision making (PJDM) process that leads to professional competence. Focusing on PJDM outcomes allows for the development of broader and more adaptable professional competences. These in turn allow for 
evaluation to be focused on thematic problem solving processes rather than simple behavioural outcomes.

\section{9. 'It's Just Superstition I Suppose ... I've Always Done Something on Game Day': The Construction of Everyday Life on a University Basketball Team}

Cherrington, J. (2014). International Review for the Sociology of Sport, 49(5), 509-525

Research in sport has tended to focus on 'spectacular' or 'extra-ordinary' experiences, at the expense of discussing how particular phenomena are embedded in everyday life. Drawing on ethnographic research with a university basketball team in England, the authors of this article consider the meanings that amateur players attach to basketball and how such meanings go beyond their participation in competitive games. Analysis reveals the rhythms and rituals which are important in determining the players' sense of self. It also highlights the 'carnivalesque' celebrations that allow players to temporarily disrupt the status quo and experiment with alternative identities. It is argued that the meaning of sport should not be seen as rigid, determining and predictable, but rather a creative experience that is largely dependent on the subjective appropriation of time and place.

\section{0. 'Harry walks, Fabio runs': A Case Study on the Current Relationship between English National Identity, Soccer and the English Press}

Griggs, G., \& Gibbons, T. (2014). International Review for the Sociology of Sport, 49(5) 536549

On 8 February 2012 Fabio Capello resigned from his position as manager of England's men's national association football (soccer) team. The date this decision became public coincided with the acquittal in court of Harry Redknapp following the Tottenham Hotspur FC manager being accused of tax evasion. In this paper the authors use these events to explore the current relationship between English national identity, soccer and the English national press. Thematic analysis revealed that journalists often adopted a 'Little Englander' mentality with regards to their attitudes towards Capello, due to his Italian nationality. Contrary to this, the press frequently depicted Redknapp as a typically 'English' working-class hero linking him with nostalgic references to a bygone 'golden era' of English soccer. These findings illustrate the main ways in which the English press continue to present English national identity via their soccer related coverage as insular and rooted in the past.

\section{Relative Age Effect in Lower Categories of International Basketball}

Saavedra, M., Gutierrez, O., Fernandez, J.J., Fernandez, D. \& Eiras, G. (2014). International Review for the Sociology of Sport, 49(5), 526-535 
This paper looks into the existence of the relative age effect in the male and female World Championships played between 2005 and 2010 in the U17, U19 and U21 categories. The variables registered were dates of birth, the category of the competition, gender, height and official statistics of each player obtained from the International Basketball Federation (FIBA). A clear relative age effect was found (in both male and female categories) fading with age, being higher in the U17 category, slightly less but also significant in the U19 category, and no significant effect found in U21. The performance difference of the players in the male and female categories however hardly varies with regard to the year-quarter of birth.

\section{Complex and Nonlinear Pedagogy and the Implications for Physical Education}

Chow, J. Y., \& Atencio, M. (2014). Sport, Education and Society, 19(8) 1034-1054.

The emergence of game behaviours as a consequence of the dynamic interactions of the learner, the game environment and the task constraints within the game context highlights the nonlinear and complex nature of how learning of game skills can occur. While there is increasing recognition that teaching and learning should be seen from a complex and nonlinear perspective, the challenge is to provide teachers with ideas on how to deliver lessons and activities that are underpinned by specific pedagogical practices from this perspective and in alignment with emerging curricular guidelines. In this paper, key features of complex and nonlinear pedagogy are discussed and exemplified through a Singaporean physical education context. Practical implications are shared on how lessons/activities (soccer) based on aspects of complex and nonlinear pedagogy can be delivered in school sport and physical education settings. 